\title{
Could conservation management be prioritised during captive wildlife experiences?
}

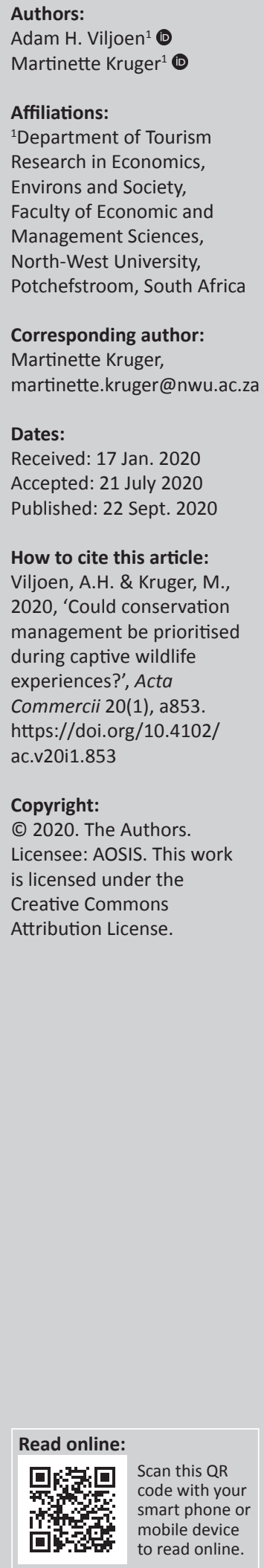

Orientation: Wildlife rehabilitation centres and sanctuaries are experiencing increased pressure from conservationists and animal rights activists to eradicate captive wildlife interactions.

Research purpose: Conservation management is a crucial aspect of these establishments. Research on how to enhance conservation management in these establishments, particularly in a South African context, is scant - a gap that this research fills.

Research design, approach and method: This study was approached from the regulatory ontological stance, neo-positivism, and was exploratory. Furthermore, it made use of a quantitative research method in the form of a structured online questionnaire. Through a convenience snowball sampling method 172 responses were obtained. The data were exported to Microsoft Excel@ and analysed by using SPSS Version 25. The multivariate analyses included factor analyses and a stepwise linear regression analysis.

Main findings: Exploratory factor analyses identified the motives (socialisation and participation, volunteerism and education, novelty and value, and wellness and interaction), key management aspects (staff, conservation, visitor, accessibility and service management) and interpretation needs of visitors (subjective, objective, interactive and interpersonal interpretation). Because conservation management is a primary objective of sanctuaries and rehabilitation centres, this factor was the dependent variable. The linear regression analyses determined which individual motivations, key management aspects and interpretation factors had the greatest influence in enhancing conservation management.

Practical/managerial implications: The results provided valuable insight regarding management practices, marketing strategies and interpretation preferences of visitors to enhance captive wildlife experiences. The findings may help change the negative perceptions surrounding the management of captive wildlife establishments.

Contribution/value-add: Organisations and the public need to realise that the end goal is not to criticise or ridicule the establishments, but rather to provide guidelines on how to manage the visitor experience by emphasising conservation management principles sustainably.

Keywords: captive wildlife experiences; conservation management; sanctuaries; rehabilitation centres; visitor experience; interpretation needs; visitor motive.

\section{Introduction}

Private initiatives and non-governmental organisations (NGOs) such as wildlife rehabilitation centres and sanctuaries are often overlooked for the contributions made towards conservation, albeit the impact of human-wildlife interaction (European Alliance of Rescue Centres and Sanctuaries [EARS] 2019). The fundamental distinction between wildlife rehabilitation centres and wildlife sanctuaries is rooted in the ability to either reintroduce the wildlife back into the natural environment or take stewardship and provide refuge for species that might not be reintroduced back into the wild (Fair Trade in Tourism [FTT] 2018). The latter is especially true for vulnerable, young and orphaned wildlife resulting from poaching and destruction of natural habitats. Therefore, centres and sanctuaries perform a vital role in the conservation of wildlife, as well as the protection of indigenous endangered species. It should be noted that a few centres and sanctuaries are permitted to breed certain species in captivity to ensure future survival or to diversify the gene pool.

On the other hand, rescued wildlife, predominantly those animals that have experienced high levels of human-wildlife interaction (such as zoo and circus animals), are often unadaptable to reintroduction. Therefore, sanctuaries are often used as a refuge. The conservation efforts and management practices of centres and sanctuaries consequently require critical investigation to ensure the sustainability, feasibility and continued success of the operations. Regarding the management of captive wildlife, various organisations in South Africa are in the process of 
developing guidelines and best practices or have already executed the guidelines. These include FTT (2018), Southern Africa Tourism Services Association (SATSA 2019) and the National Council of Societies for the Prevention of Cruelty to Animals (NSPCA 2019), who have a dedicated wildlife protection unit that investigates complaints lodged by the public and conservation activists.

What is the role that centres and sanctuaries need to fulfil? Are these establishments creating opportunities that might be exploited to the advancement of particular species as well as encouraging conservation by educating visitors and contributing to scientific research? What is ideal in balancing both human and wildlife welfare during interactions, passive viewing or physical handling? Moreover, the interpretation offerings and learning components at centres and sanctuaries are of vital importance for disseminating information to the public. Numerous empirical papers and studies on nature-based destinations (especially on national parks in South Africa) have identified the importance of learning, knowledgeseeking and interpretation preferences as the motives of national park visitors (Chikuta, Du Plessis \& Saayman 2017; Kruger, Viljoen \& Saayman 2017; Saayman \& Dieske 2015; Slabbert \& Du Plessis 2013; Viviers \& Slabbert 2012). However, the literature on wildlife rehabilitation centres and sanctuaries, particularly in a South African context, is limited.

\section{Aims, objectives and research rationale}

To fill the gap in the literature, the purpose of this exploratory research is to identify the critical drivers of conservation management at wildlife sanctuaries and rehabilitation centres from a demand-side perspective. Conservation management was extracted as a key visitor experience management factor because it is supposed to form the essence of captive wildlife experiences. The independent variables for the research included (1) visitor motives, (2) the management aspects visitors regard as important for a memorable experience and (3) visitors' interpretation needs. The results of this research provide valuable first-time insight regarding management practices, marketing strategies and the interpretation preferences of visitors to enhance captive wildlife experiences, especially conservation management. This research is especially valuable considering that wildlife is a significant component of the South African tourism attraction sector. According to Dr Uwe Hermann, Director of the Tshwane University of Technology's (TUT) centre for sustainable tourism, tourists cite value for money, natural scenery and wildlife experience as top reasons to visit South Africa. However, they have become more conscious of captive animal welfare and are more likely to talk about negative experiences (Kormorant 2019).

Moreover, the latest South African Tourism (SAT) Annual Report 2017/2018 (SAT 2019) identified wild animal interactions as a key issue that had an adverse effect on leisure tourism. Continued negative media reports on the unethical practices linked to animal encounters have damaged the country's brand as an advocate of wildlife conservation (SATSA 2019). This may lead to increased pressure from conservationists and animal rights activists to eradicate captive wildlife interactions (Kormorant 2019). Identifying the determinants that may be used to enhance conservation management in captive wildlife establishments is therefore not only a timely research effort but also necessary to manage and develop this sector sustainably.

\section{A conceptual framework and tested hypotheses of the research}

Literature about wildlife in captivity ranges from various perspectives such as consumption to captivity status in order to distinguish and adequately relate the importance thereof. With this in mind, the authors propose the following conceptual framework for captive wildlife experiences, which we refer to as a 'captive wildlife management system'. As illustrated in Figure 1, the two prominent establishments under investigation in this research are wildlife sanctuaries and asylums and wildlife rehabilitation centres. To facilitate the conceptualisation and discussion, the management spectrum is placed at the core of the figure, because the indicators (captivity conditions, human-wildlife interaction, reintroduction possibility and the low-consumptive usage of wildlife) are also determinants of the various levels of conservation between the centres and sanctuaries.

Within the management spectrum, each establishment is subjected to the four indicators outlined in the centre of the figure. Note that the establishments may move along the different axes, as indicated, depending on the degree of interaction, the level of confinement, the degree of consumptive use and the likelihood of reintroduction. The captivity conditions include captive and semi-captive settings with various degrees of confinement (Shani \& Pizam 2008). Additionally, this includes the use of natural or simulated (artificial) environments. Sanctuaries are often captive

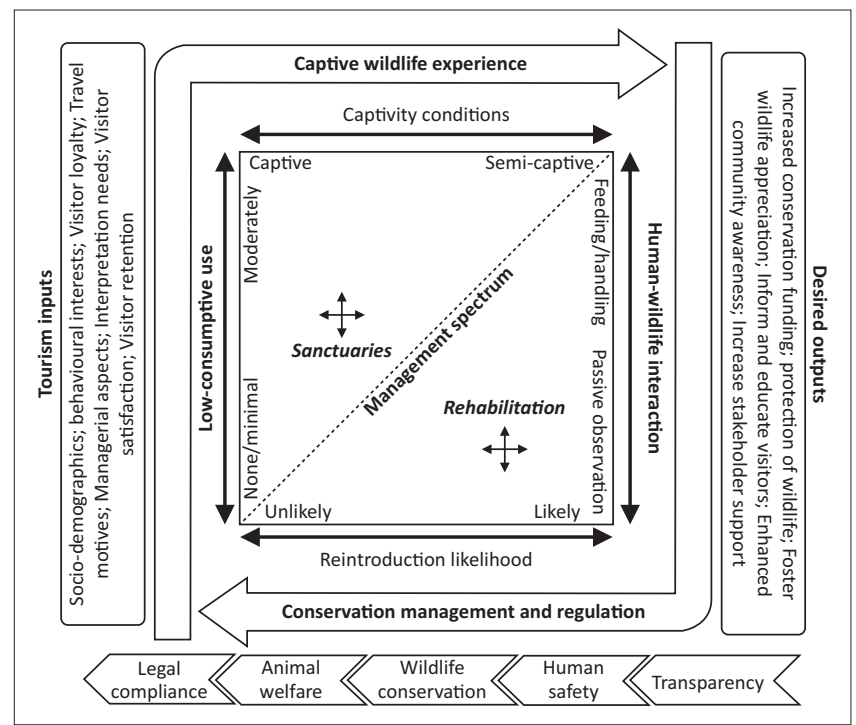

FIGURE 1: Captive wildlife management system. 
settings, whilst rehabilitation centres may range from semicaptive to captive confinement conditions (Higginbottom 2004). Human-wildlife interaction is considered as one of the essential aspects to regulate, whilst others believe that the degree of interaction is manageable. For example, passive observation would be on the lower impact of the spectrum, whilst feeding and handling wildlife have a much more significant impact. Orams (2002) reveals that feeding wildlife may have detrimental effects such as the alteration of natural behaviour patterns and population, dependency and habituation, aggression, health impacts, disease and injury. To evaluate reintroduction likelihood, various methods are employed along with different considerations such as the age of the wildlife being reintroduced, whether the animal is wild bred versus captive bred and the associated costs to determine the suitability of release (Fischer \& Lindenmayer 2000; Mathews et al. 2005). The likelihood of reintroduction is, therefore, highly situation dependent.

Furthermore, it is expected that reintroduction will almost exclusively be wildlife that has been rehabilitated because many animals that are in the care of sanctuaries will have great difficulty to adapt in the wild (Banes, Galdikas \& Vigilant 2016). Concerning the low-consumptive usage of wildlife, the authors suggest that a scale is employed in determining the level of the usage within the broader lowconsumptive classification. The use of 'none or minimal' to 'moderately low-consumption usage' classification is therefore proposed. In South Africa, FTT (2018) developed a set of good practice guidelines for the captive wildlife sector. Fair Trade in Tourism promotes the use of five pillars, namely legal compliance, animal welfare, wildlife conservation, human safety and transparency. These five pillars are indicated at the bottom of Figure 1. As previously indicated, the regulation of wildlife captivity establishments differs across countries, societies, cultures and species, and the five pillars represent a South African regulatory attempt. These pillars are separated from Figure 1 because at the time of writing there was no authority to enforce these guidelines.

Ideally, to reach the desired outputs, no visitors would be permitted to these establishments; however, because the welfare and upkeep of wildlife are expensive, with no or little support from the government, the tourism input from related activities are needed. The role of the tourism input should, however, be seen as an input-output system because, besides the associated costs of caring for the wildlife, it does provide an opportunity to educate the public on wildlife. Additional expected outputs include increasing conservation funding, protecting wildlife, fostering wildlife appreciation, informing and educating visitors, enhancing community awareness and increasing stakeholder support. The management of this input-output system is, however, of crucial importance.

\section{Development of the tested hypotheses}

Because this research was conducted from a visitor demandside perspective, as illustrated on the far left of Figure 1, identifying the input of visitors to captive wildlife settings such as their sociodemographics, behavioural interests, visitor loyalty and travel motives may contribute to memorable captive wildlife experiences. However, the emphasis should also be on enhancing conservation management during these experiences. The question that remains is what are the aspects that visitors to these types of establishments regard as important when it comes to conservation management? To find the answer, three variables $\left(\mathrm{H}_{1-3}\right)$ were tested in the research: the visitor management aspects they regard as necessary for a satisfying experience $\left(\mathrm{H}_{1}\right)$, visitors' motives to captive wildlife establishments $\left(\mathrm{H}_{2}\right)$ and their interpretation needs and preferences $\left(\mathrm{H}_{3}\right)$.

\section{Managing the visitor experience in captive wildlife settings}

Regarding the management of the visitor experience, numerous studies have identified the factors visitors regard as crucial for a memorable or satisfying experience. These studies were, however, mainly conducted in a national park or natural event setting. Collectively, the results from the studies show that factors such as accessibility (DeBruyn \& Smith 2009; Knight 2010; Montag, Patterson \& Freimund 2005), proximity to the wildlife (Finkler \& Higham 2004; Orams 2000; Schänzel \& McIntosh 2000; Wolf \& Croft 2012; Ziegler, Dearden \& Rollins 2012), the possibility of clear observation (DeBruyn \& Smith 2009; Finkler \& Higham 2004; Kruger, Viljoen \& Saayman 2013; Orams 2000) and interpretation (De Witt, Van Der Merwe \& Saayman 2014; Foxlee 2001; Kruger, Van der Merwe \& Saayman 2018; Ziegler et al. 2012) are essential for a successful wildlife-viewing experience. There is, however, no universally accepted set of management factors, and they are mostly dependent on the type of setting and the experience offered.

Compared to zoo and aquarium research, research is limited regarding captive non-zoo experiences. However, some research has investigated the demand for wildlife tourism and the role that visitors play (Moorhouse et al. 2015), the role of captive breeding for conservation (Nogueira-Filho \& Nogueira 2004) and the role of visitors as assessors of unethical wildlife use (Moorhouse, D'Cruze \& Macdonald 2017). The major problem within the literature is to clearly define what captive wildlife settings include (Packer \& Ballantyne 2012; Reiser 2018), as well as to what degree human-wildlife interaction is permitted (Cohen 2019). In the present research, the focus is on captive wildlife within rehabilitation centres and sanctuaries. Except for zoos and aquariums, many sanctuaries, orphanages and centres are very proconservation and do not allow visitors. Because the low-consumptive use of tourist visitation is a driver that influences the tourism experience at captive wildlife establishments, visitor experiences need to be managed, especially with conservation in mind. The following hypothesis was therefore formulated:

$\mathbf{H}_{1(0)}$ : Visitor experience management is not related to conservation management.

$\mathbf{H}_{1}$ : Visitor experience management is related to conservation management. 


\section{Motives of visitors to captive wildlife settings}

Various studies have identified the profile, motives and expectations of visitors to wildlife settings, particularly to South African national parks. Collectively, the findings of these studies indicate that visitors to national parks are homogeneous in terms of their sociodemographic profile: they are mainly from Gauteng (the economic hub of the country), in their forties, well educated, prefer longer lengths of stay and have considerable spending power (Engelbrecht, Kruger \& Saayman 2014; Kruger \& Saayman 2014; Kruger, Saayman \& Hermann 2014; Kruger et al. 2017). Previous research conducted on the motives of these visitors identified the push factor, escape from the daily routine (Botha, Saayman \& Kruger 2016; Hermann et al. 2016; Kruger, Saayman \& Saayman 2010; Kruger et al. 2017; Saayman \& Dieske 2015). Other push motives consistent across the board include factors such as novelty (Kruger et al. 2010; Van der Merwe \& Saayman 2008), nostalgia (Kruger et al. 2010; Van der Merwe \& Saayman 2008) and personal gain (Viviers \& Slabbert 2012). Pull factors include education and learning about nature (Botha et al. 2016; Kruger et al. 2010; Saayman \& Dieske 2015), participating in recreational and leisure activities (Hermann et al. 2016), as well as the park attributes, nature experiences and photography (Kruger et al. 2010).

Regarding captive wildlife settings, the current research (2015-2019) primarily makes a distinction between captive zoo and aquarium visitor experiences and captive non-zoo visitors. Research on captive zoo visitor experiences has indicated that visitors are primarily attracted to zoos for a fun day out, to relax and for the benefit of children (Higginbottom 2004). In a more in-depth investigation, Packer and Ballantyne (2016) indicate that differences between zoo and aquarium visitors are noticeable. Both zoo and aquarium visitors emphasise the social aspects of the visit (quality time with family and friends). However, the aquarium visitors had a higher percentage (nearly double) of visitors who indicated learning as the highest priority. Unfortunately, the motives of visitors to other captive wildlife settings have not yet been identified. The authors argue that visitors' motives could play an essential role in the way they regard conservation management, and therefore, the following hypothesis was formulated:

$$
\begin{aligned}
& \mathbf{H}_{2(0)} \text { : Visitor motivation is not related to conservation } \\
& \text { management. }
\end{aligned}
$$

$\mathbf{H}_{2}$ : Visitor motivation is related to conservation management.

\section{Interpretation needs and preferences in captive wildlife settings}

Kuo (2002), Stewart et al. (1998), Tilden (1977) and Ward and Wilkinson (2006) identify four types of interpretation, namely attended versus unattended; personal versus impersonal, primary, secondary and tertiary; and hard versus soft. Tilden (1977) was the first to classify different types of interpretation. He identified attended (in person) and unattended (not in person) interpretation, which is also closely related to Ward and Wilkinson's (2006) personal and impersonal interpretation.
Attended or personal interpretation refers to interpretation that involves person-to-person contact, such as game drives or educational talks, whereas unattended or impersonal interpretation refers to interpretation with no personal contact, such as educational displays or exhibits. Over the years, the classifications have, however, grown into more complicated types (Botha et al. 2016). For example, Stewart et al. (1998) distinguish between three types of interpretation: primary interpretation (visitor centres, displays, audio-visual, staff assistance, models, on-site panels, an interpretive shelter, leaflets, guidebooks), secondary interpretation (verbal and written commentary offered on concessionaire activities, commentary offered on transport to and from the site) and tertiary interpretation (advertising on posters on- and off-site, $\mathrm{TV}$, radio, merchandise, pictorial books, informal conversation with park staff, other visitors or accompanying friends and family). This distinction between primary, secondary and tertiary interpretation correlates well with Kuo's (2002) soft interpretation aimed at educational management (Stewart etal.'s primary interpretation), supported by hard interpretation (Stewart et al.'s secondary and tertiary interpretation) that focuses on physical, regulatory and economic management aspects. Soft interpretation refers to the specific educational message presented to visitors at interpretation centres, whereas hard interpretation refers to viewing platforms (physical), rules about behaviour (regulatory) and higher fees in peak seasons (economic). Based on these classifications, it is clear that interpretation is a necessary component of the visitor experience (hard or secondary and tertiary interpretation), and it relates to the experience (soft or primary interpretation).

Regarding visitors' interpretation needs and the preferences of visitors to wildlife tourist attractions, the majority of research is encapsulated within national parks and zoos. The interpretation offerings within captive wildlife tourist attractions are displayed usually through a wide variety of media. For example, zoos make use of a variety of media from personal face-to-face interaction with guides and rangers to written communication for information dissemination (Woods 1998). In a national park setting, applying a similar classification as Stewart et al. (1998), Botha et al. (2016) found that primary followed by secondary interpretation services as well as knowledgeable staff are deemed important by visitors. Interpretation is furthermore not only for educational purposes but is also related to accessibility and signage. However, determining the interpretation needs and preferences of visitors is a systematic continuum, especially with the advances in technology. Returning to rehabilitation centres and sanctuaries, the type of interpretation would surely differ from the type of interpretation employed in zoos and aquariums. Additionally, the interpretation needs and preferences of visitors to centres and sanctuaries are unfortunately unknown. Hence, the following hypothesis was formulated:

$\mathbf{H}_{3(0)}$ : Visitor interpretation needs and preferences are not related to conservation management.

$\mathbf{H}_{3}$ : Visitor interpretation needs and preferences are related to conservation management. 
The hypotheses mentioned above were tested to determine which set of factors has the most significant influence on enhancing conservation management in a captive wildlife setting.

\section{Research methods and design}

This study was approached from the regulatory ontological stance, neo-positivism, and was exploratory.

\section{Study design}

The study made use of a quantitative research method in the form of a survey research design by means of a structured questionnaire that consisted of four sections. Section A captured sociodemographic details (gender, age, home language, level of education, nationality and province of origin, marital status, annual income, travel party, group size, the number of persons paid for, expenditure during the visit, type of sanctuary or rehabilitation centre visited and when the decision was made). Section B captured motivational factors, measuring 22 items on a five-point Likert scale of agreement ranging from 1 (strongly agree) to 5 (strongly disagree). On a similar five-point Likert scale of agreement, Section $C$ measured 33 key management aspects, and Section D measured 28 interpretation needs and preferences. The measurement methods were assessed according to validity and reliability criteria. All four sections satisfied the criteria for content validity. The statements included in Section B were based on previous studies on travel motives to nature-based destinations including those by Schänzel and McIntosh (2000), Foxlee (2001), Finkler and Higham (2004), Wolf and Croft (2012), Ziegler et al. (2012) and Kruger et al. (2013). These statements ranged from escape, socialisation, novelty, education, well-being and lifestyle. However, the authors also created statements linked to conservation and how this aspect in the context of sanctuaries and rehabilitation centres motivates visitors. Aspects such as volunteering and the extent of wildlife interaction preferred were also included. Section C was based on the findings on managerial aspects within national parks (Engelbrecht et al. 2014) and ranged from statements related to general management, service, logistics, accessibility and staff management. Because the research identified the determinants of enhanced conservation management, the authors created particular statements measuring respondents' awareness of the establishments' conservation efforts and wildlife management. Section D was based on and adapted from previous studies on the interpretation as discussed in the literature review (Botha et al. 2016; Kuo 2002; Stewart et al. 1998; Tilden 1977; Van Loggerenberg, Saayman \& Kruger 2015; Ward \& Wilkinson 2006) and included a variety of interpretation statements related to primary, secondary and tertiary interpretation. Whilst many of the statements measured in sections B, C and D were based on existing literature, the authors also created statements mainly related to management and experience at sanctuaries and rehabilitation centres.

\section{Study population, sampling method and data collection}

Because of the nature of the research and the ethical implications, the researchers were not granted permission to conduct the research on-site at sanctuaries and rehabilitation centres in South Africa. Because visitors to these establishments may be defined as a population of wildlife tourists challenging to access, an electronic survey was deemed the only way to gain access to the population. Moreover, it is likely that the people who follow these establishments on Facebook are conservation-oriented and have visited a sanctuary or rehabilitation centre before. Therefore, a convenience snowball sampling method was used to gain access to these visitors. The data were therefore collected by means of a selfadministrated online questionnaire distributed on the social media pages of willing centres and sanctuaries, as well as Facebook groups associated with wildlife conservation in South Africa. Convincing establishments and conservation agencies to form part of the research was a time-consuming and challenging process, as establishments were fearful that their practices would be scrutinised. Various Facebook pages were randomly selected; however, only five were willing to assist with the research. Table 1 shows a breakdown of the willing establishments and conservation groups that formed part of the research as well as their number of Facebook followers.

The questionnaire was designed on the Research Analytics online survey software QuestionPro and was hosted online from 28 June 2017 to 14 November 2018. The participating establishments and agencies were reminded weekly to post the link to the survey continuously. Unfortunately, despite the researchers' best efforts, a total of 183 questionnaires were collected. Incomplete questionnaires were not included in further analysis, resulting in 172 useable questionnaires. Statistics regarding the number of visitors to the sanctuaries and rehabilitation centres are currently unknown and impossible to accurately determine. If the sample size is based on the total number of the participating pages' Facebook followers (28 992), according to Krejcie and Morgan's formula (1970), for a population (N) of 30000 , a sample of 379 respondents would be seen as appropriately representative and could consequently validate the results. The authors acknowledge the limitation of an unrepresentative sample; however, because this is an exploratory research, the results are nonetheless considered sufficiently relevant and significant to consider. The results are especially valuable given the increasing pressure on wildlife sanctuaries and rehabilitation centres to manage their conservation efforts as

TABLE 1: Breakdown of participating groups.

\begin{tabular}{lc}
\hline Type of establishment or organisation & Number of Facebook followers \\
\hline Wildlife centre and sanctuary & 5078 \\
Rehabilitation centre & 7414 \\
Conservation agency & 10408 \\
Domestic travel page & 4510 \\
Tertiary institution & 1582 \\
Total number of followers & 28992 \\
\hline
\end{tabular}


well as the visitor experience sustainably and in an overly cautious manner in order to avoid adverse effects on wildlife.

\section{Ethical consideration}

Ethical approval was obtained from the Economic and Management Sciences Research Ethics Committee (EMSREC) at the North-West University (ethical clearance number NWU-00146-17-A4, 14 December 2017). The study did not target any vulnerable groups and only targeted adult respondents (18 years of age and older). A cover letter indicated the purpose of the research, informed consent details, stated that respondents' participation in this research was entirely voluntary and that they would receive no form of compensation. If they wanted to halt participation in the study, they could do so without judgement. Responses from each individual were not identified, ensuring respondents' anonymity, but rather the results were presented in aggregate (the results of the group were presented as a whole), and no individual results were reported.

\section{Data analysis}

The data were exported to Microsoft Excel and analysed using SPSS Version 25 (2018, 2019). The analysis was performed in three stages: a descriptive analysis to profile the respondents, three-factor analyses (visitor experience management aspects, motives to visit and interpretation needs) and a stepwise linear regression analysis. For the latter, conservation management was the dependent variable. The analysis was used to identify which individual motivation, key management aspects, as well as interpretation factors had the greatest influence in enhancing conservation management.

A principal component of exploratory factor analyses (EFA) was performed on the 33 key management aspects, 22 motivation items and 28 interpretation items to explain the variance-covariance structure of a set of variables through a few linear combinations of these variables. Because it can be expected that there would be correlations between the different factors, an Oblimin rotation with Kaiser normalisation was done to improve the interpretability of each factor structure. The Kaiser-Meyer-Olkin (KMO) measure of sampling adequacy was used to determine whether the covariance matrix was suitable for factor analysis. A KMO $>0.7$ is deemed acceptable (Kaiser \& Rice 1974). Kaiser's criteria for the extraction of all factors with eigenvalues larger than one were used because they were considered to explain a significant amount of variation in the data. All items with a factor loading $>0.4$ were considered as contributing to a factor, and all items with loadings $<0.4$ were regarded as not correlating significantly with this factor. Any item that cross-loaded onto two factors with a factor loading $>0.4$ were categorised in the factor where interpretability was best. To test the reliability of the identified factors in the EFA, reliability coefficients (Cronbach's alpha) and inter-item correlations were calculated. All factors with a reliability coefficient above 0.6 were considered acceptable in this study. The average inter-item correlations were also computed as another measure of reliability; these, according to Cohen (1988), should lie between 0.15 and 0.55 . Factor scores were calculated as the average of all items contributing to a particular factor to interpret them on the original five-point Likert scale.

For the regression analysis, the relationship between the factors and the dependent variable (conservation management) was investigated firstly by using Spearman's rho, which indicated that all the factors had a medium $(r=0.3)$ to large effect $(r=0.5)$. In the regression analyses, the $R^{2}$ value gives the proportion of variance in the dependent variable and is explained through the predictors included in the model. An $R^{2}$ value of 0.25 or larger can be considered as practically significant (Ellis \& Steyn 2003). The adjusted $R^{2}$ value indicates how much variance in the outcome would be accounted for if the model had been derived from the population from which the sample was taken. It also takes into account the number of explanatory variables in the model (Field 2016). The adjusted $R^{2}$ value, therefore, gives an idea of how well the regression model generalises, and ideally, its value needs to be the same or very close to the value of $R^{2}$ (Field 2016).

\section{Stage 1: Profile of the respondents}

Table 2 shows the profile of the respondents. The majority of the respondents were male, on average 42 years old, residing in Gauteng or the Western Cape Province, Afrikaans speaking and married with an undergraduate qualification and a high annual income. Specific species sanctuaries were visited the most, followed by wildlife sanctuaries. Respondents mainly made a spontaneous decision to visit with their families (immediate and extended). They travelled in groups of four adults and one child and were financially responsible for an average of three persons. During their visit, the highest spending was on accommodation and transport, with an average total spending of R3770.00.

\section{Stage 2: Results of the factor analyses}

\section{Factor analysis 1: Visitors' experience management aspects and identifying the dependent variable}

The EFA identified five key management factors (Table 3). Based on the mean values, considering their last visit to a sanctuary or rehabilitation centre, respondents agreed the most with staff management (1.83), followed by service management (2.02), accessibility management (2.10) and visitor management (2.16). Conservation management obtained the lowest mean value (2.28), which is a concern considering that it should be these types of establishments' main priority. Therefore, conservation management is the dependent variable of the research to help enhance this critical aspect. The following hypotheses were formulated:

\footnotetext{
$\mathbf{H}_{0(1 \mathrm{a})}$ : Staff management not related to conservation management.

$\mathbf{H}_{1 \mathbf{a}}$ : Staff management is related to conservation management.

$\mathbf{H}_{\mathbf{0 ( 1 \mathbf { b }}}$ : Visitor management is not related to conservation management.

$\mathbf{H}_{1 \mathrm{~b}}$ : Visitor management is related to conservation management.
} 
TABLE 2: Respondents' profiles.

\begin{tabular}{|c|c|}
\hline Characteristic & Descriptive results \\
\hline Gender & Male, $72 \%$; female, $28 \%$ \\
\hline Average age & 41.93 years \\
\hline Home language & Afrikaans, $61 \%$; English, $37 \%$; other, $2 \%$ \\
\hline Marital status & Married, $55 \%$; dating, $15 \%$; single, $13 \%$; engaged, $8 \%$; divorced, $5 \%$; civil union, $4 \%$; widowed, $1 \%$ \\
\hline The highest level of education & $\begin{array}{l}\text { Undergraduate, } 36 \% \text {; Honours/4-year degree, } 21 \% \text {; high school, } 21 \% \text {; middle school or junior high school, } 18 \% \text {; } \\
\text { secondary education (high school ), } 4 \%\end{array}$ \\
\hline Province of residence & $\begin{array}{l}\text { Gauteng, } 43 \% \text {; Western Cape, } 20 \% \text {; Eastern Cape, } 10 \% \text {; Free State, } 8 \% \text {; Northern Cape, } 6 \% \text {; KwaZulu-Natal, } 6 \% \text {, } \\
\text { Limpopo, 3\%; North West, 3\%; Western Cape } 2 \%\end{array}$ \\
\hline Annual income & $\begin{array}{l}\text { > R672 001, 19\%; R20 001-R140 000, 17\%; < R20 000, 13\%; R305 001-R431 000, 13\%; R431 001-R552 000, 13\%; } \\
\text { R140 001-R221 000, 10\%; R221 001-R305 000, 8\%; R552 001-R672 000, 8\% }\end{array}$ \\
\hline Type of sanctuary or rehabilitation centre visited & $\begin{array}{l}\text { Specific species sanctuary, } 37 \% \text {; wild life sanctuary, } 31 \% \text {; wildlife rehabilitation centre, } 20 \% \text {; specific species } \\
\text { rehabilitation centre, } 12 \%\end{array}$ \\
\hline Decision made to visit the sanctuary or rehabilitation centre & Spontaneously, $51 \%$; more than 1 month prior, $25 \% ; 1$ week prior, $10 \% ; 1$ month prior, $9 \% ; 2$ to 3 weeks prior, $6 \%$ \\
\hline Travel group composition & $\begin{array}{l}\text { Family (spouse and children), } 35 \% \text {; extended family (spouse, children, parents, siblings), } 23 \% \text {; myself plus friends, } \\
17 \% \text {; myself and spouse/significant other, } 16 \% \text {; travelling with a tour group, } 6 \% \text {; myself only, } 3 \% \text {; myself plus } \\
\text { spouse/significant other, } 16 \%\end{array}$ \\
\hline The average number of adults in the travel group & 3.77 \\
\hline The average number of children in the travel group & 1.14 \\
\hline The average number of adults in the travel group paid for & 1.99 \\
\hline The average number of children in the travel group paid for & 0.76 \\
\hline The average number of persons paid for & 2.61 \\
\hline The average age of the children & 8.54 years \\
\hline \multicolumn{2}{|l|}{ Average spending during the visit (ZAR) } \\
\hline Entrance fees & R328.15 \\
\hline Return transport & R916.03 \\
\hline Accommodation & R1346.99 \\
\hline Food & R554.51 \\
\hline Beverages & R303.03 \\
\hline Clothing and footwear & R191.95 \\
\hline Activities & R382.32 \\
\hline Jewellery and souvenirs & R177.40 \\
\hline Donations & R123.77 \\
\hline Average total spending & R3770.90 \\
\hline Average spending per person & R2576.08 \\
\hline
\end{tabular}

TABLE 3: Results of the exploratory factor analyses on the visitor experience management aspects.

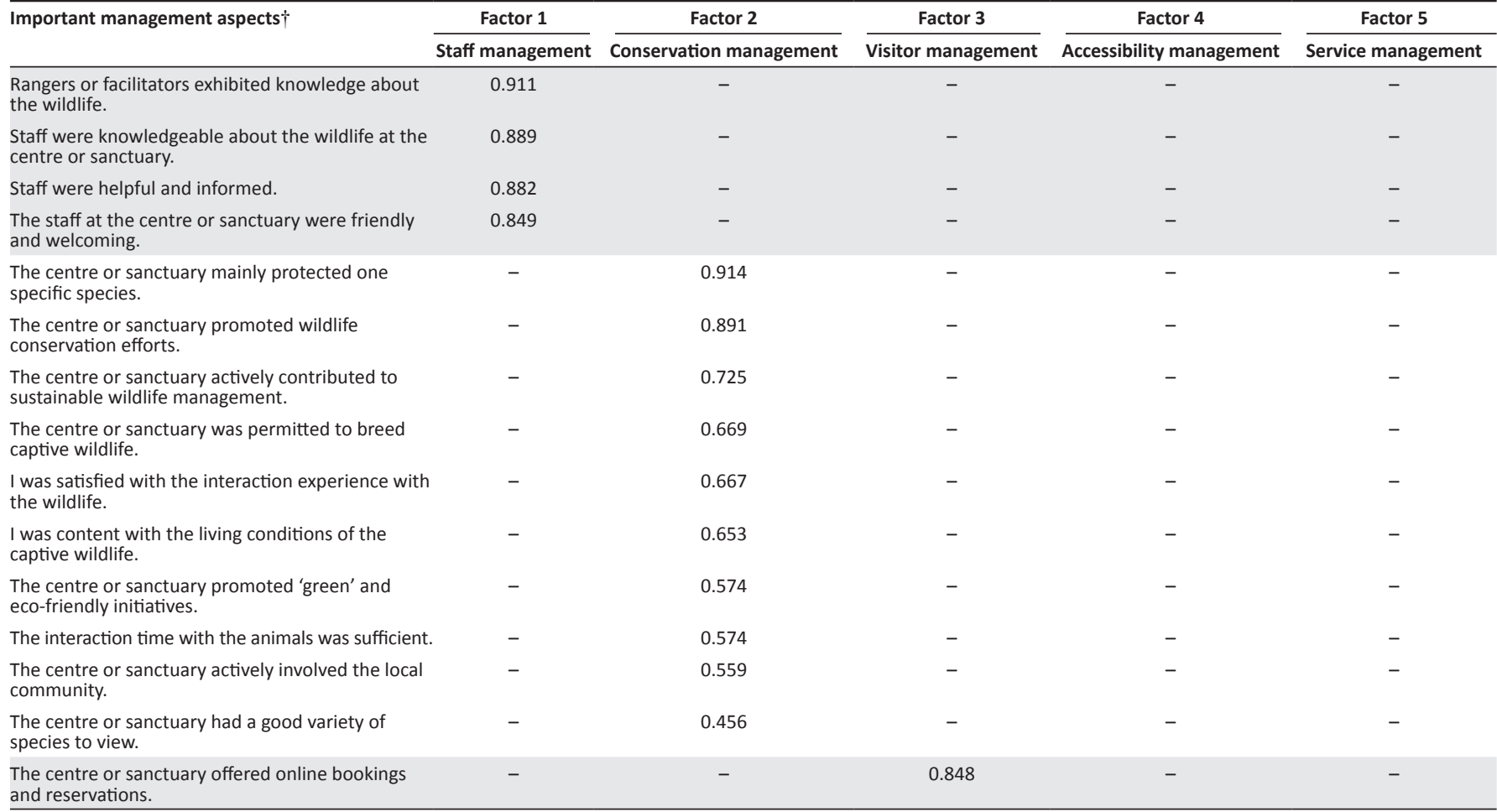


TABLE 3 (Continues...): Results of the exploratory factor analyses on the visitor experience management aspects.

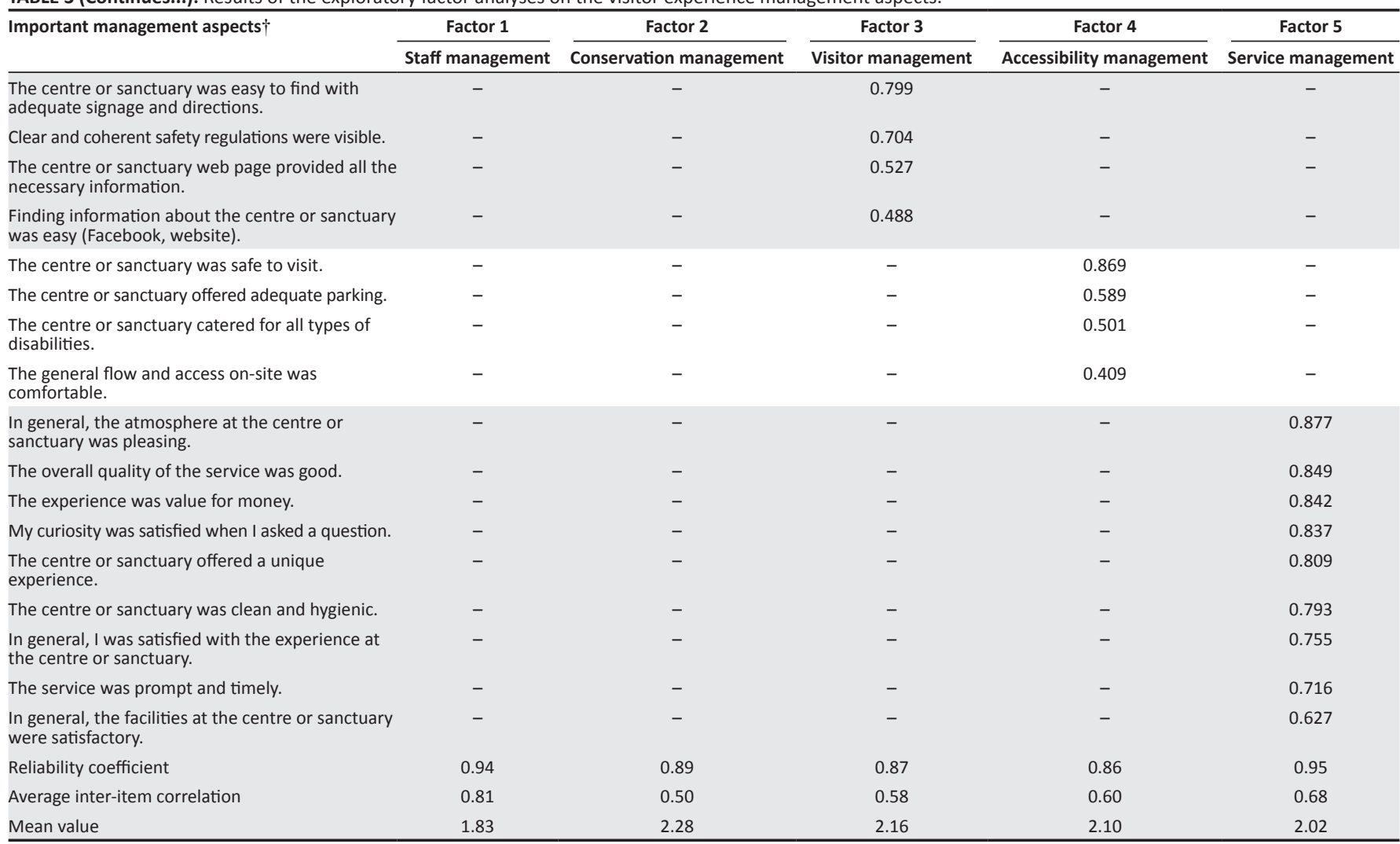

$\dagger$, The Kaiser-Meyer-Olkin measure of sampling adequacy was 0.95; Bartlett's test of sphericity was significant $\left(x^{2}[528]=5234.96, p<0.05\right)$; the proportion of variance explained was $75 \%$.

$\mathbf{H}_{0(1 \mathrm{c})}:$ Accessibility management is not related to conservation management.

$\mathbf{H}_{1 \mathrm{c}}$ : Accessibility management is related to conservation management.

$\mathbf{H}_{\mathbf{0 ( 1 \mathrm { d } )}}$ : Service management is not related to conservation management.

$\mathbf{H}_{1 \mathrm{~d}}$ : Service management is related to conservation management.

\section{Factor analysis 2: Motivation to visit sanctuaries and rehabilitation centres}

Socialisation and participation (2.23) was the most important motivation to visit sanctuaries and rehabilitation centres (Table 4). This was followed by volunteerism and education (2.32), wellness and interaction (2.81) and finally novelty and value (3.17). Consequently, the following hypotheses are proposed:

$\mathbf{H}_{\mathbf{0 ( 2 )}}$ : Socialisation and participation are not related to conservation management.

$\mathbf{H}_{2 \mathbf{a}}$ : Socialisation and participation are related to conservation management.

$\mathbf{H}_{\mathbf{0 ( 2 b}}$ : Volunteerism and education are not related to conservation management.

$\mathbf{H}_{2 \mathbf{b}}$ : Volunteerism and education are related to conservation management.

$\mathbf{H}_{0(2 \mathrm{c})}:$ Novelty and value are not related to conservation management.

$\mathbf{H}_{2 c}$ : Novelty and value are related to conservation management.

$\mathbf{H}_{0(2 \mathrm{~d})}$ : Wellness and interaction are not related to conservation management.

$\mathbf{H}_{2 \mathrm{~d}}$ : Wellness and interaction are related to conservation management.
Factor analysis 3: Interpretation needs at sanctuaries and rehabilitation centres

Regarding the interpretation needs at sanctuaries and rehabilitation centres (Table 5), respondents agreed the most that interpersonal interpretation (2.08) is required at the establishments. This was followed by subjective interpretation (2.28), objective interpretation (2.46) and interactive interpretation (2.46). The formulated hypotheses:

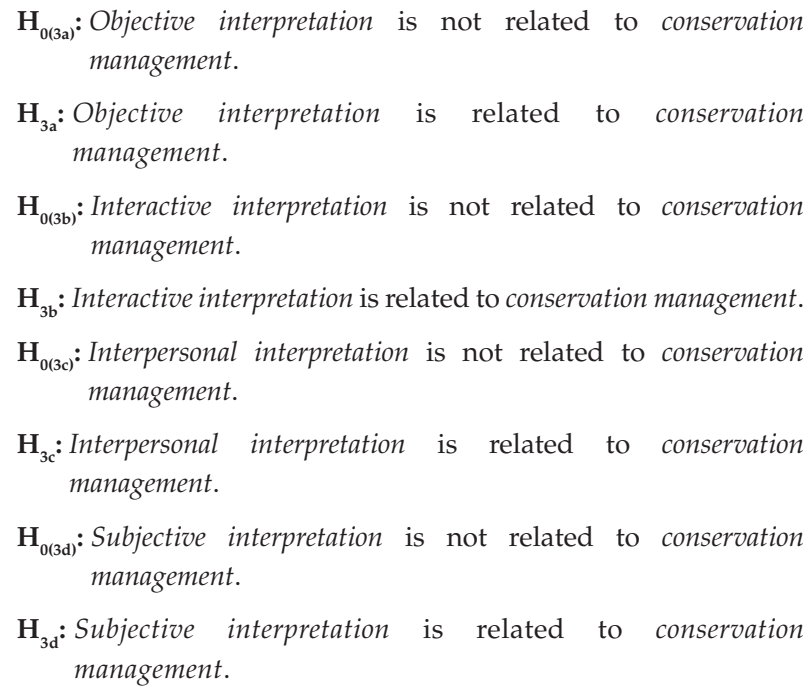

\section{Stage 3: Results from the linear regression analysis to prioritise conservation management}

As illustrated in Figure 2, a linear regression analysis was performed to show whether there is a significant 
TABLE 4: Results of the exploratory factor analyses of the motivation to visit. Motives to visit the sanctuary or rehabilitation centre $\dagger \quad$ Factor 1

\begin{tabular}{|c|c|c|c|}
\hline Socialisation and participation & Volunteerism and education & Novelty and value & Wellness and interaction \\
\hline
\end{tabular}

To spend time with family and friends.

0.760
0.756
0.720
0.715
0.623
0.599
0.588
0.426

To explore a new destination.

To participate in activities (game drives or walking with wildlife).

To relax and escape from the daily routine.

To gain knowledge about wildlife in captivity.

To photograph wild animals.

To interact with wildlife.

To visit the rehabilitation centre or sanctuary's main attractions (e.g. cheetahs).

To volunteer

To contribute to wildlife conservation.

To see the release of wildlife back into their natural habitat.

To learn more about endangered species.

To actively live out a passion for wildlife.

To appreciate endangered species.

To partake in novelty visits (new trends).

Visiting friends and relatives in the area.

Because the centre or sanctuary is child-friendly.

To visit these centres, as it is affordable and provides a value for money experience.

Visiting the rehabilitation centre or sanctuary enhances and contributes to my overall well-being.

Visiting the rehabilitation centre or sanctuary forms part of my lifestyle.

The assurance of seeing a variety of wildlife or endangered

species that might elude one in national parks.

To touch or handle or feed wildlife.

Reliability coefficient

Socialisation and part 0.760

Average inter-item correlation

\begin{tabular}{ll}
- & 0.790 \\
- & 0.706 \\
- & 0.690 \\
- & 0.554 \\
- & 0.542 \\
- & 0.400 \\
\hline
\end{tabular}

Mean value

$\begin{array}{lcc}- & 0.400 & - \\ - & - & 0.746 \\ - & - & 0.720 \\ - & - & 0.697 \\ - & - & 0.475\end{array}$

$\dagger$, The Kaiser-Meyer-Olkin measure of sampling adequacy was 0.87; Bartlett's test of sphericity was significant $\left(x^{2}[231]=1938.56, p<0.05\right)$; the proportion of variance explained was $63 \%$.

TABLE 5: Results of the exploratory factor analyses on interpretation needs.

Interpretation needs and preferencest

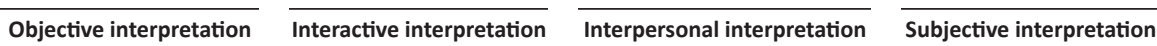

\section{Information on regional archaeology (i.e. human history} and prehistory).

Information on regional hydrology (i.e. the scientific study of the movement, distribution and quality of the water).

Information on regional geography (i.e. the study of

physical features of the earth and atmosphere).

Information on regional climatology (i.e. the scientific study of climate).

Information on nearby historical sites.

Information on regional ecology (i.e. relationships of 0.883

organisms to one another and surroundings or

environment).

Information on the surrounding cultures and communities.

Information on astrology (i.e. star gazing).

Information on the regional flora (e.g. trees, flowers and

plants).

Information on the regional fauna (e.g. birds, insects, mammals and predators).

Virtual reality should be delivered (e.g. virtual tours). Audio or visual media should be present (e.g. videos). Audio media should be delivered (e.g. bird or animal sounds).

Technology-based media would be interesting (e.g. interactive touchscreens).

Media presented should be game-like or entertaining (e.g. short quizzes, puzzles, 'did you know' facts).

Souvenirs related to interpretation centre should be available for purchase in order to remember the experience.

Visual media should be present (e.g. pictures and diagrams).

0.848

0.843

0.757

0.742

0.734

0.688

0.654

0.637

0.620

$-$

0.79

$\begin{array}{cc}- & 0.769\end{array}$

- 0.713

0.700

$-$

0.600

$\begin{array}{cc}- & 0.561\end{array}$

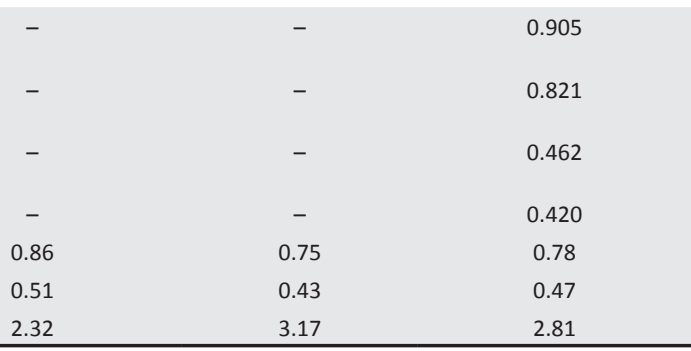


TABLE 5 (Continues...): Results of the exploratory factor analyses on interpretation needs.

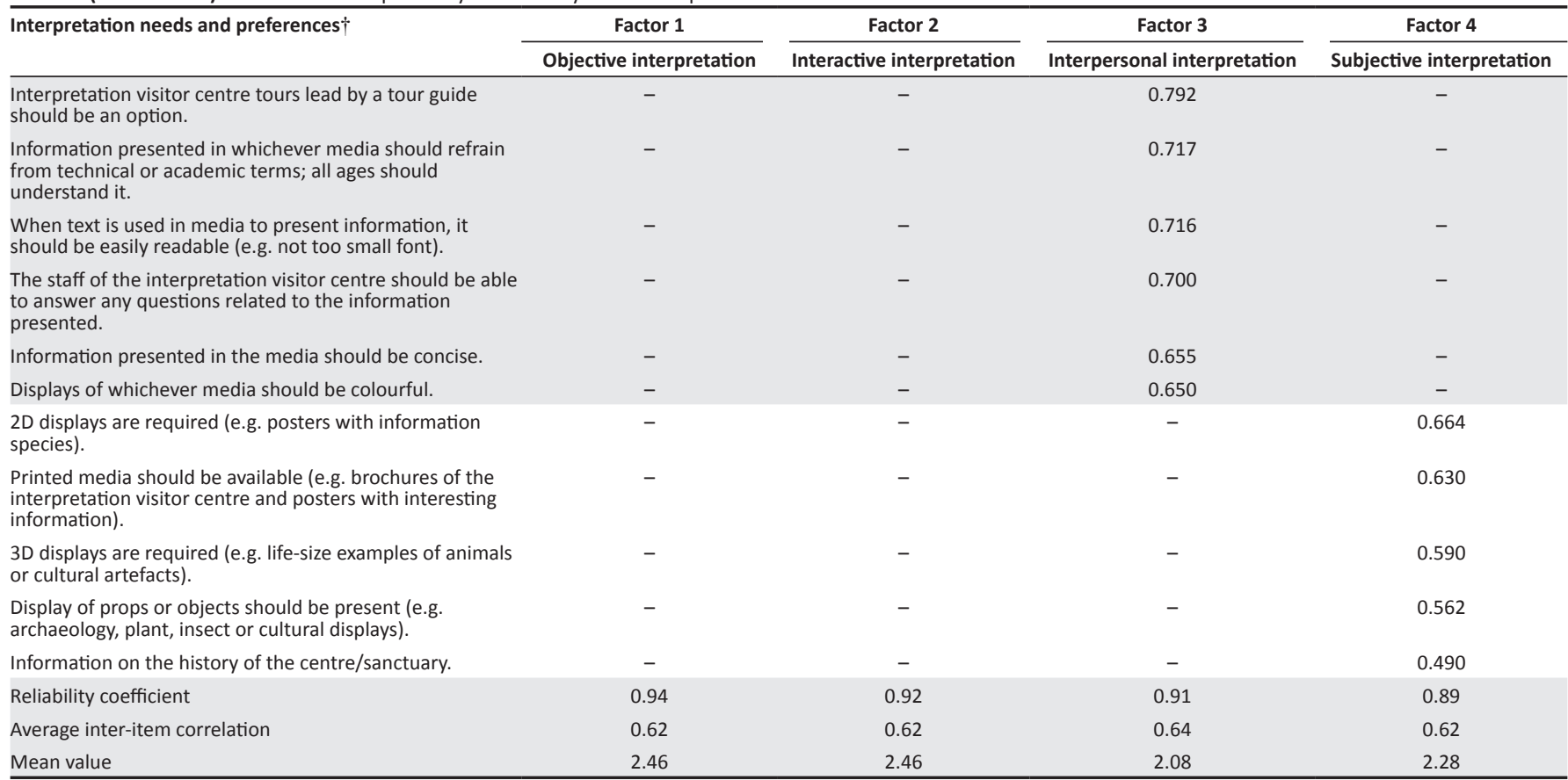

$\dagger$, The Kaiser-Meyer-Olkin measure of sampling adequacy was 0.93; Bartlett's test of sphericity was significant $\left(x^{2}[378]=3941.26, p<0.05\right)$; the proportion of variance explained was $73 \%$.

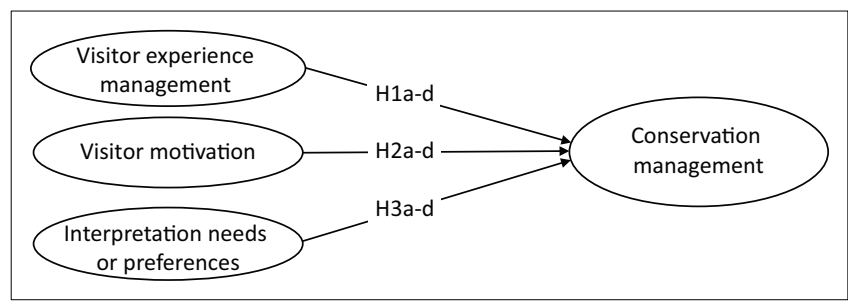

FIGURE 2: Hypothesised regression model.

relationship between conservation management and the other key management factors, along with the motivational factors and interpretation factors.

A standard least-squares regression analysis was performed to identify the determinants of conservation management. A stepwise, backwards and forwards regression analysis was also performed, and the eighth model in the backwards regression analysis had the best results. The $R$ value (0.885) represented a simple correlation and indicated a good level of prediction for the model. The $R^{2}$ value $(0.783)$ is the proportion of the variance in the dependent variable that can be explained by the independent variables. The adjusted $R^{2}$ had a similar value $(0.776)$. The significant variables in the models explained $78 \%$ of the variance. The $F$-ratio indicated that the overall regression model was a good fit for the data $(F[5,154]=111.105, p=0.001 *)$. The independent variables statistically predicted the dependent variable in the models significantly. These results suggest that the model was a good fit for the data.

The statistically significant independent determinants of conservation management are indicated in Table 6. The motive socialisation and participation, as well as the visitor experience management factors accessibility and service management, were
TABLE 6: The determinants of enhanced conservation management.

\begin{tabular}{|c|c|c|c|c|c|}
\hline \multirow[t]{2}{*}{ Determinants } & \multicolumn{2}{|c|}{$\begin{array}{l}\text { Unstandardised } \\
\text { coefficients }\end{array}$} & \multirow{2}{*}{$\begin{array}{c}\text { Standardised } \\
\text { coefficient }\end{array}$} & \multirow[t]{2}{*}{$\mathbf{t}$} & \multirow[t]{2}{*}{ Sig. } \\
\hline & B & SE & & & \\
\hline (Constant) & 0.103 & 0.114 & & 0.906 & 0.366 \\
\hline \multicolumn{6}{|l|}{ Visitor motivation } \\
\hline Socialisation and participation & 0.111 & 0.051 & 0.116 & 2.173 & $0.031 *$ \\
\hline Wellness and interaction & 0.083 & 0.043 & 0.100 & 1.924 & $0.056 * *$ \\
\hline \multicolumn{6}{|c|}{ Interpretation needs and preferences } \\
\hline Interpersonal interpretation & 0.058 & 0.044 & 0.056 & 1.315 & 0.190 \\
\hline \multicolumn{6}{|l|}{ Visitor experience management } \\
\hline Accessibility management & 0.332 & 0.076 & 0.328 & 4.381 & $0.001 *$ \\
\hline Service management & 0.431 & 0.078 & 0.425 & 5.541 & $0.001 *$ \\
\hline
\end{tabular}

$\mathrm{SE}$, standard error; t, t-value; Sig., Significance level

*, Statistically significant, $p<0.05 ; * *$, statistically significant, $p<0.10$

statistically significant $(p<0.05)$. The positive beta coefficients indicate positive relationships, thereby supporting $\mathrm{H}_{1 c^{\prime}} \mathrm{H}_{1 \mathrm{~d}}$ and $\mathrm{H}_{2 \mathrm{a}}$. The motive wellness and interaction showed a statistically significant positive relationship at a $10 \%$ level of significance, thereby supporting $\mathrm{H}_{2 \mathrm{~d}}$. Because this is a preliminary study, the authors regard $p<0.10$ as suggestive of a significant effect that warrants further study (Zar 2010). Interpersonal interpretation was the only interpretation needs and preference factor that was included in the model but was not statistically significant. The positive beta coefficient indicates that this factor can also enhance conservation management.

\section{Discussion}

This novel research identified the factors related to visitor experience management, visitor motivation and visitor interpretation needs within a captive wildlife experience setting, specifically sanctuaries and rehabilitation centres in South Africa. Conservation management was identified as a 
critical visitor management factor, and for the research, it was extracted as the dependent variable. This was done because conservation management should be a core function at captive wildlife establishments, but the visitor experience should be managed concurrently. This research has the following findings and implications.

\section{Visitor experience management and conservation management}

Confirming the notion that there is no universally accepted set of visitor experience management factors and that the type and nature of the tourism setting determine the set of management factors, the researchers identified five distinct visitor experience management factors within a captive wildlife setting. In order of importance, these are staff, service, accessibility, visitor and, lastly, conservation management. The combination of visitor experience management factors differs compared to those identified in the literature review except for accessibility management, which was also identified by Montag et al. (2005), DeBruyn and Smith (2009) and Knight (2010); visitor management, which is similar to the good practice guideline developed by the FTT (2018); and human safety. Even though the FTT (2018) emphasises wildlife conservation as another key guideline, the low rating of conservation management is worrisome. Visitors regard other management aspects related to the visitor experience as more important than conservation management. The regression analysis revealed that accessibility and service management had a unique relationship with conservation management. These results imply that conservation management needs to be integrated into all facets of the visitor experience.

Enhancing and prioritising conservation management within each of the accompanying management facets will result in practical guidelines that could easily be enforced. For example, to enhance service management, the staff (on all levels) should be aware of the conservation goals set by the establishment and be trained to identify potential gaps in day-to-day operations. It should be made abundantly clear that conservation is the goal, and therefore, the principles of ecotourism will be in effect. Thus, reservations will be electronically handled to minimise paper use; if printed media are used, it should be on recycled paper; souvenirs will be of ethical and local origin; and in food operations, seasonal and locally sourced ingredients are to be used. The aforementioned can also enhance both staff and visitor management. Accessibility management had a statistically significant relationship, implying that particular attention should also be paid to enhance this aspect. Establishments should therefore ensure that they are accessible to all visitors, including disabled visitors, and that the visitor experience is designed to cater to these visitors' needs. By implementing these types of conservation initiatives, visitors are made aware (consciously or subconsciously) about the importance of conservation management.

\section{Visitor motivation and conservation management}

The results of this study both confirm and contradict existing literature and reveal new motives, thereby confirming that the combination of motives is greatly influenced by the type of wildlife setting experience, in this case, captive wildlife experiences. Four motives were identified, namely socialisation and participation, volunteerism and education, wellness and interaction, as well as novelty and value. The combination of motives has not yet been identified in the literature and can therefore be regarded as distinct to captive wildlife experiences. The importance of socialisation and participation confirms the findings by Higginbottom (2004) and Packer and Ballantyne (2016), who also identify socialisation as an important motive to visit captive zoo settings, but contradict the majority of research conducted in a national park setting, where escaping remains the main visitor motive. Education, part of the combined motive volunteerism and education, is also supported as a key motive for visiting captive wildlife settings as identified by Higginbottom (2004) and Packer and Ballantyne (2016), as well as national parks (Botha et al. 2016; Kruger et al. 2010; Saayman \& Dieske 2015). However, it appears, for visitors to sanctuaries and rehabilitation centres, that to get actively involved in the form of volunteering is also a critical motive to visit these types of establishments. Hermann et al. (2016) identify participating in activities as an important motive for national park visitors; however, the combined motive, wellness and interaction, is another motive novel to the research indicating that visitors to captive wildlife settings regard these experiences as contributing towards their well-being and lifestyle, but that they want interaction with the wildlife to be assured.

The regression analysis revealed that socialisation and participation along with wellness and interaction were the motives that had the greatest influence on enhancing conservation management. To prioritise conservation management through the motive socialisation and participation, establishments can create programmes that are grouporientated and family-friendly whilst being immersive. Immersive activities are often also 'soft' activities, which in general lack any physical danger, require little to no skill and seem safe to most participants. Moreover, the activities should offer transformative wildlife viewing experiences. These experiences should create the illusion of being near the wildlife whilst still being a 'hands-off' approach. Hence, physical proximity should be exchanged with remote viewing that still offers an intimate feeling. An example used in birdwatching is the use of viewing platforms and hides so that visitors might be able to view certain species-specific attributes.

Regarding the factor wellness and interaction, the personal well-being and lifestyle items are indicative that visitors do perceive increases in personal well-being and that visitation forms part of a lifestyle. Because these are subjective to each, a more bespoke approach should be followed depending on various visitor attributes, which are easily gained through a 
quick visitor preference survey with every booking made. In general, the establishments should be willing to prioritise conservation management above visitor preferences, but in a very conscious manner. Visitors have to be informed that specific behaviour should be avoided and that particular attention is given in providing a proconservation experience.

\section{Visitor interpretation needs and preferences and conservation management}

Four interpretation need factors were identified, proposing a new typology of interpretation specifically for captive wildlife experiences, namely, in order of importance, interpersonal, subjective, interactive and objective interpretation. Interpersonal interpretation is related to personal interpretation as identified by Ward and Wilkinson (2006), primary interpretation by Stewart et al. (1998) and Kuo's (2002) hard interpretation. However, whilst the classification above mainly refers to physical structures such as interpretation centres and viewing platforms, interpersonal interpretation in the present research also includes aspects related to how the interpretation messages are presented, for example, regarding font type, size, colour and media. Subjective and objective interpretation are similar to secondary and tertiary interpretation as classified by Stewart et al. (1998) and Botha et al. (2016) and unattended interpretation by Tilden (1977) and Kuo's (2002) soft interpretation. A distinct interpretation factor identified in the research was interactive interpretation, which has, to the authors' knowledge, not yet been identified in the literature as a form of interpretation. This factor refers to the application of technology, such as touchscreens and interactive puzzles, to educate visitors.

The regression analysis did not reveal any statistically significant relations for the interpretation factors. However, interpersonal interpretation was the only factor included in the model, indicating that this form of interpretation has the potential to enhance conservation management. It nevertheless remains important to enhance all forms of interpretation, as education is key to conservation management. Because objective interpretation revealed increased preferences for information on nearly all regional aspects, establishments have the opportunity to have historical perspective on the development of the area or region, as well as on other species (not necessarily on 'display') that are indigenous. This could ensure that visitors have a well-rounded and intellectually stimulating experience that is completed with the wildlife viewing. It is essential to provide the information in an interpersonal manner by making use of well-educated tour guides, ensuring that the information is comprehensible and free from too many academic terms and jargon and that staff are ready to answer a variety of questions from visitors of all ages and backgrounds. The use of the interpersonal interpretation media should relate to the social aspects being family-friendly and easily understood by children. This, in turn, also contributes to enhancing the visitor experience management factors, namely staff and visitor management. Visitors regarded subjective interpretation as an essential form of interpretation, implying that conservation efforts should be visually displayed to inform visitors of the establishments' history and conservation goals. Both 2D and 3D displays can further help enhance this interpretation factor.

\section{Conclusion}

This research tackled a timely topic, namely managing visitor experiences, whilst still enhancing conservation in captive wildlife settings other than zoos, national parks and aquariums, which have, to date, received the most research attention. The purpose of the research was to identify which aspects of the visitor experience need to be managed to enhance conservation management at sanctuaries and rehabilitation centres in South Africa. It was clear from the research that visitors have a misconception regarding the role and function of these types of establishments. This was evident in the low rating of conservation management. It appears that visitors to these establishments seek a relaxing and fun excursion whilst expecting their interaction to involve getting as close as possible to the wildlife. The latter should be addressed by management and marketers of sanctuaries and rehabilitation centres to avoid becoming 'greenwashed' petting zoos. The finding from this research is the first step in addressing this pertinent issue. The research has the following valuable contributions:

- For the first time, the tourism input, which involves the visitor experience at captive wildlife establishments, was illustrated with a conceptual framework. This framework thereby greatly contributes towards the literature on captive wildlife experiences and advocates that the tourism input is unfortunately unavoidable, often for the financial sustainability of the establishments. However, it cautions that the tourism input needs to be managed in line with the conservation principles and guidelines set out by the establishments' management.

- A set of distinct visitor experience factors, visitor motives and interpretation needs to captive wildlife experiences were identified. Whilst comparisons are evident, the combination and strength of the factors mostly differ from the findings in the existing literature, making another valuable contribution to the captive wildlife literature.

- Conservation management was the dependent variable in the research, and the results revealed which combination of the visitor experience and preference factors had the most significant influence on enhancing this critical factor. The contributing factors are, however, different from the aspects that were revealed to be important, as indicated by the factor analyses. The challenge, therefore, is for sanctuaries and rehabilitation centres to find a balance between attracting visitors and satisfying their needs, whilst at the same time enhancing conservation management. This research contributes to a better understanding of how to create this intricate balance.

\section{Limitations and direction for future research}

The authors acknowledge the small sample size, which was mainly a result of both sanctuaries and rehabilitation centres' 
as well as the general public's reluctance to form part of the research. This research also only captured the perceptions of a population that had access to Facebook and were following certain pages. The results, therefore, cannot be generalised to the whole population. The authors hope that this research can help change the negative perceptions surrounding the management of captive wildlife establishments and that organisations and the public realise that the end goal is not to criticise or ridicule the establishments, but rather to provide guidelines on how to manage the visitor experience by emphasising conservation management sustainably. The identified factors therefore shed valuable light onto the needs and preferences of visitors to sanctuaries and rehabilitation centres. However, more research is necessary to validate the findings. It is further recommended that a supply-side analysis be conducted to identify possible gaps between visitors' and management's perceptions. The guidelines set out by FTT (2018) need to be incorporated, especially measuring visitors' awareness of these important guidelines.

\section{Acknowledgements}

This work is based on the research supported by the National Research Foundation (NRF). The authors are grateful to all the respondents who were willing to form part of the research.

\section{Competing interests}

The authors declare that they have no financial or personal relationships that may have inappropriately influenced them in presenting this article.

\section{Authors' contributions}

A.H.V. conceptualised the research framework, developed the questionnaire and managed the survey. He further provided valuable practical implications for the research. M.K. conceptualised the research idea, structured the article, developed the measuring instrument and coordinated the survey. She further performed all statistical analyses as well as quality insurance of the overall document.

\section{Funding information}

This research received no specific grant from any funding agency in the public, commercial or not-for-profit sectors.

\section{Data availability statement}

The data that support the findings of this study are available on request from the corresponding author (M.K). The data are not publicly available because of ethical restrictions.

\section{Disclaimer}

All opinions, findings and conclusions or recommendations expressed in this material belong to the authors and the NRF does not accept any liability in this regard.

\section{References}

Banes, G.L., Galdikas, B.M. \& Vigilant, L., 2016, 'Reintroduction of confiscated and displaced mammals risks outbreeding and introgression in natural populations, as evidenced by orang-utans of divergent subspecies', Nature: Scientific Reports 6(22026), 1-9. https://doi.org/10.1038/srep22026

Botha, E., Saayman, M. \& Kruger, M., 2016, 'Expectations versus experience-the Kruger National Park's interpretation services from a regional approach', Journal of Ecotourism 15(2), 158-183. https://doi.org/10.1080/14724049.2016.1178753

Chikuta, O., Du Plessis, L. \& Saayman, M., 2017, 'Nature-based travel motivations for people with disabilities', African Journal of Hospitality, Tourism and Leisure 6(1), 1-16. https://doi.org/10.1080/21568316.2018.1447509

Cohen, E., 2019, 'Interacting with wild animals', in P.L. Pearce (ed.), Tourist behaviour. The essential companion, pp. 220-240, Edward Elgar Publishing, Northampton, MA.

Cohen, J., 1988, Statistical power analysis for the behavioural sciences, 2nd edn., Routledge, Hillsdale, NJ.

DeBruyn, T.D. \& Smith, T.S., 2009, 'Managing bear-viewing to minimise human impacts on the species in Alaska', in J. Hill \& T. Gale (eds.), Ecotourism and environmental sustainability. Principles and practice, pp. 109-124, Ashgate Publishing, Farnham.

De Witt, L., Van Der Merwe, P. \& Saayman, M., 2014, 'Critical ecotourism factors applicable to national parks: A visitor perspective', Tourism Review International 17(3), 179-194. https://doi.org/10.3727/154427213X13838418677005

Ellis, S.M. \& Steyn, H.S., 2003, 'Practical significance (effect sizes) versus or in combination with statistical significance ( $p$-values): Research note', Management Dynamics 12(4), 51-53.

Engelbrecht, W.H., Kruger, M. \& Saayman, M., 2014, 'An analysis of critical success factors in managing the tourist experience at Kruger National Park', Tourism Review International17(4), 237-251. https://doi.org/10.3727/154427214X13910101597120

European Alliance of Rescue Centres and Sanctuaries, 2019, The role of rescue centres and sanctuaries, viewed 05 June 2019, from http://ears.org/rescue-centres-andsanctuaries/.

Fair Trade in Tourism, 2018, Good practice guidelines for captive wildlife in South Africa, viewed 04 June 2019, from www.fairtrade.travel.

Field, A.P., 2016, Discovering statistics using IBM SPSS, Sage Publication, Los Angeles,

Finkler, W. \& Higham, J., 2004, 'The human dimensions of whale watching: An analysis based on viewing platforms', Human Dimensions of Wildlife 9(2), 103-117. https://doi.org/10.1080/10871200490441757

Fischer, J. \& Lindenmayer, D.B., 2000, 'An assessment of the published results of animal relocations', Biological Conservation 96(1), 1-11. https://doi.org/10.1016/ S0006-3207(00)00048-3

Foxlee, J., 2001, 'Whale watching and Hervey Bay', Australian Parks and Leisure 4(3), 17-18.

Hermann, U.P., Van der Merwe, P., Coetzee, W.J. \& Saayman, M., 2016, 'A visito motivational typology at Mapungubwe National Park and World Heritage Site', Acta Commercii 16(1), 1-7. https://doi.org/10.4102/ac.v16i1.315

Higginbottom, K. (ed.), 2004, Wildife tourism: Impacts, management and planning, Common Ground Publishing, Altona.

Kaiser, H.F. \& Rice, J., 1974, 'Little jiffy, mark IV', Educational and Psychological Measurement 34(1), 111-117. https://doi.org/10.1177/001316447403400115

Knight, J., 2010, 'The ready-to-view wild monkey: The convenience principle in Japanese wildlife tourism', Annals of Tourism Research 37(3), 744-762. https:// doi.org/10.1016/j.annals.2010.01.003

Kormorant, 2019, Captive wildlife facilities in the tourism spotlight, viewed 04 June 2019, from https://kormorant.co.za/63531/captive-wildlife-facilities-tourism-spotlight/.

Kruger, M. \& Saayman, M., 2014, 'The determinants of visitor length of stay at the Kruger National Park', Koedoe 56(2), 1-11. https://doi.org/10.4102/koedoe. v56i2.1114

Kruger, M., Saayman, M. \& Hermann, U.P., 2014, 'First-time versus repeat visitors at the Kruger National Park', Acta Commercii 14(1), 1-9. https://doi.org/10.4102/ ac.v14i1.220

Kruger, M., Saayman, M. \& Saayman, A., 2010, 'Expenditure-based segmentation of visitors to the Tsitsikamma National Park', Acta Commercii 10(1), 137-149. https://doi.org/10.4102/ac.v10i1.123

Kruger, M., Van der Merwe, P. \& Saayman, M., 2018, 'A whale of a time! An experiencebased typology of visitors to a South African whale-watching festival', Journal of Outdoor Recreation and Tourism 24(1), 35-44. https://doi.org/10.1016/j. jort.2018.10.005

Kruger, M., Viljoen, A. \& Saayman, M., 2013, 'Who pays to view wildflowers in South Africa?', Journal of Ecotourism 12(3), 146-164. https://doi.org/10.1080/1472404 9.2013.871286

Kruger, M., Viljoen, A. \& Saayman, M., 2017, 'Who visits the Kruger National Park, and why? Identifying target markets', Journal of Travel \& Tourism Marketing 34(3), 312-340. https://doi.org/10.1080/10548408.2016.1156618

Kuo, I.L., 2002, 'The effectiveness of environmental interpretation at resourcesensitive tourism destinations', International Journal of Tourism Research 4(2), 87-101. https://doi.org/10.1002/jtr.362

Mathews, F., Orros, M., McLaren, G., Gelling, M. \& Foster, R., 2005, 'Keeping fit on the ark: Assessing the suitability of captive-bred animals for release', Biological Conservation 121(4), 569-577. https://doi.org/10.1016/j.biocon.2004.06.007 
Montag, J.M., Patterson, M.E. \& Freimund, W.A., 2005, 'The wolf viewing experience in the Lamar Valley of Yellowstone National Park', Human Dimensions of Wildlife 10(4), 273-284. https://doi.org/10.1080/10871200500292843

Moorhouse, T.P., Dahlsjö, C.A., Baker, S.E., D'Cruze, N.C. \& Macdonald, D.W., 2015, 'The customer isn't always right - Conservation and animal welfare implications of the increasing demand for wildlife tourism', PLoS One 10(10), 1-15. https://doi. org/10.1371/journal.pone.0138939

Moorhouse, T.P., D'Cruze, N.C. \& Macdonald, D.W., 2017, 'Unethical use of wildlife in tourism: What's the problem, who is responsible, and what can be done?', Journal of Sustainable Tourism 25(4), 505-516. https://doi.org/10.1080/09669582.2016. 1223087

National Council of Societies for the Prevention of Cruelty to Animals, 2019, What to do with wildlife?, viewed 05 June 2019, from https://nspca.co.za/what-to-dowith-wildlife/.

Nogueira-Filho, S.L.G. \& Nogueira, S.D.C., 2004, Captive breeding programs as an alternative for wildlife conservation in Brazil. People in nature: Wildlife management and conservation in Latin America, Columbia University Press, New York, NY.

Orams, M.B., 2000, 'Tourists getting close to whales, is it what whale-watching is all about?', Tourism Management 21(6), 561-569. https://doi.org/10.1016/S0261 5177(00)00006-6

Orams, M.B., 2002, 'Feeding wildlife as a tourism attraction: A review of issues and impacts', Tourism Management 23(3), 281-293. https://doi.org/10.1016/S02615177(01)00080-2

Packer, J. \& Ballantyne, R., 2012, 'Comparing captive and non-captive wildlife tourism' Annals of Tourism Research 39(2), 1242-1245. https://doi.org/10.1016/j. annals.2011.12.007

Packer, J. \& Ballantyne, R., 2016, 'Conceptualising the visitor experience: A review of literature and development of a multifaceted model', Visitor Studies 19(2), 128143. https://doi.org/10.1080/10645578.2016.1144023

Reiser, D., 2018, 'Will the ark sink? Captive wildlife, tourism and the human relationship to nature: Demystifying zoos', in I.B. De Lima \& R.J. Green (eds.) Wildlife tourism, environmental learning and ethical encounters, pp. 263-272, Springer, Cham.

Saayman, M. \& Dieske, T., 2015, 'Segmentation by motivation of tourists to the Kgalagadi Transfrontier Park', South African Journal of Business Management 46(2), 77-87. https://doi.org/10.4102/sajbm.v46i2.93

Schänzel, H. \& McIntosh, A.J., 2000, 'An insight into the personal and emotive context of wild life viewing at the penguin place, Otago Peninsula, New Zealand', Journal of Sustainable Tourism 8(1), 36-52. https://doi.org/10.1080/09669580008667348
Shani, A. \& Pizam, A., 2008, 'Towards an ethical framework for animal-based attractions', International Journal of Contemporary Hospitality Management 20(6), 679-693. https://doi.org/10.1108/09596110810892236

Slabbert, E. \& Du Plessis, E., 2013, 'Do socio-demographic factors influence the travel behaviour of visitors to nature-based tourism products in South Africa?', African Journal for Physical Health Education, Recreation and Dance 19(3), 639-660.

South African Tourism, 2019, South African tourism annual report 2017/2018, viewed 06 June 2019, from https://www.southafrica.net.

Southern African Tourism Services Assoiation, 2019, Animal interaction public consultation, viewed 05 June 2019, from http://www.satsa.com/animalinteraction-public-consultation-satsa-chapter-meeting/.

SPSS. 2019, IBM SPSS (Version 25) [Computer software]. Chicago, IBM.

Statistical Package for the Social Sciences version 25, 2018, computer software, International Business Machines (IBM), Chicago, IL.

Stewart, E.J., Hayward, B.M., Devlin, P.J. \& Kirby, V.G., 1998, "The "place" of interpretation: A new approach to the evaluation of interpretation', Tourism Management 19(3), 257-266. https://doi.org/10.1016/S0261-5177(98)00015-6

Tilden, F., 1977, Interpreting our heritage, 3rd edn., University of North Carolina Press, Chapel Hill, NC.

Van Der Merwe, P. \& Saayman, M., 2008, 'Travel motivations of tourists visiting Kruger National Park', Koedoe 50(1), 154-159. https://doi.org/10.4102/koedoe.v50i1.140

Van Loggerenberg, E., Saayman, M. \& Kruger, M., 2015, 'The influence of interpretation on visitors behaviour in the Kruger National Park', African Journal of Hospitality, Tourism and Leisure 4(2), 1-23.

Viviers, P. \& Slabbert, E., 2012, 'Push and pull factors of national parks in South Africa', Journal of Contemporary Management 9(1), 66-88.

Ward, C.W. \& Wilkinson, A.E., 2006, Conducting meaningful interpretation: A field guide for success, Fulcrum Publishing, Golden, CO.

Wolf, I.D. \& Croft, D.B., 2012, 'Observation techniques that minimise impacts on wildlife and maximise visitor satisfaction in night-time tours', Tourism Management 4(1), 164-175. https://doi.org/10.1016/j.tmp.2012.08.002

Woods, B., 1998, 'Animals on display: Principles for interpreting captive wildlife', Journal of Tourism Studies 9(1), 28-39.

Zar, J.H., 2010, Biostatistical analysis, 5th edn, Prentice-Hall/Pearson, Upper Saddle River, NJ.

Ziegler, J., Dearden, P. \& Rollins, R., 2012, 'But are tourists satisfied? Importance-performance analysis of the whale shark tourism industry on Isla Holbox, Mexico', Tourism Management 33(1), 692-701. https://doi.org/10.1016/j.tourman.2011.08.004 